
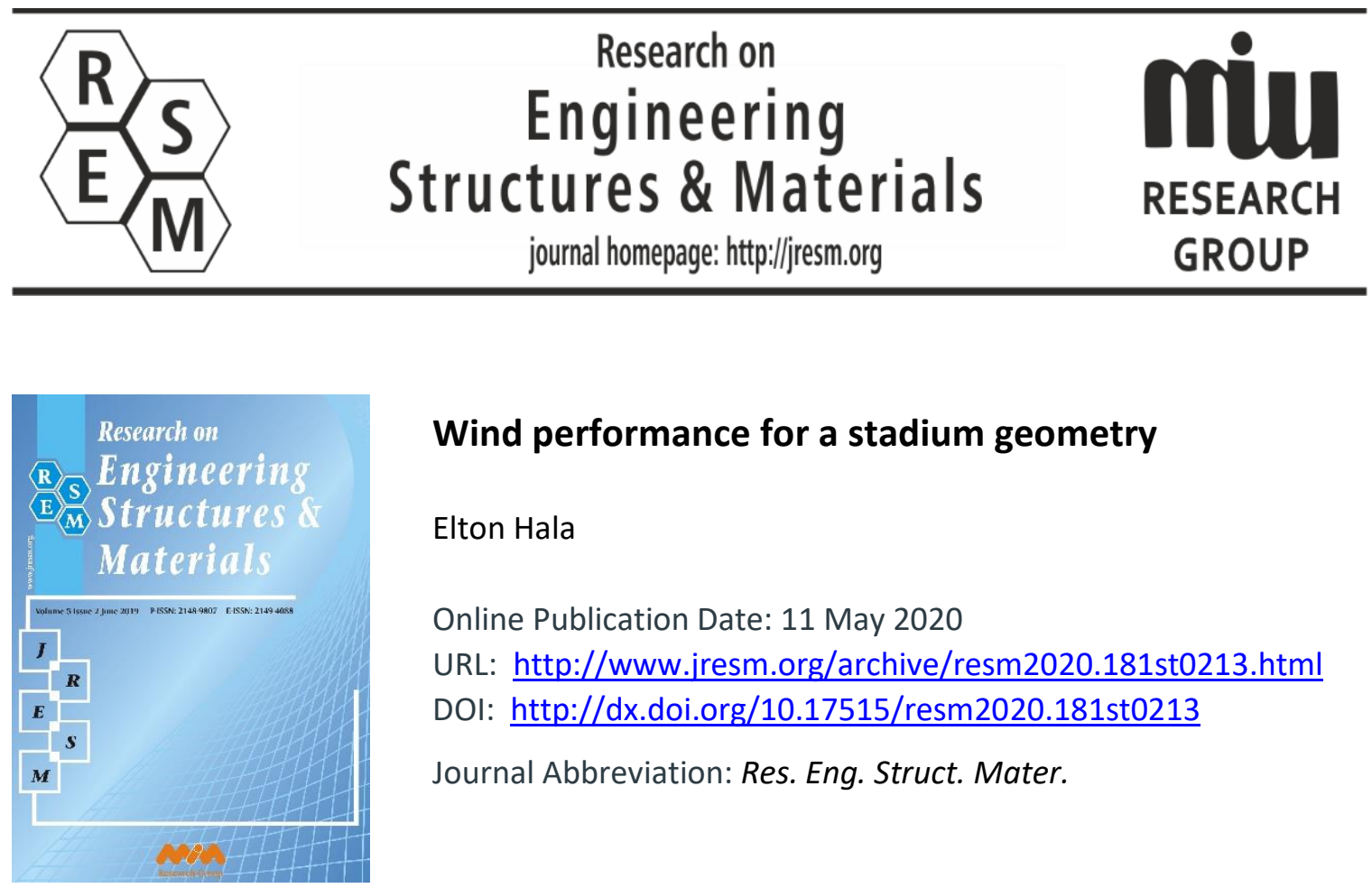

\title{
Wind performance for a stadium geometry
}

Elton Hala

Online Publication Date: 11 May 2020

URL: http://www.jresm.org/archive/resm2020.181st0213.html

DOI: http://dx.doi.org/10.17515/resm2020.181st0213

Journal Abbreviation: Res. Eng. Struct. Mater.

\section{To cite this article}

Hala E. Wind performance for a stadium geometry. Res. Eng. Struct. Mater., 2020; 6(4): 411423.

\section{Disclaimer}

All the opinions and statements expressed in the papers are on the responsibility of author(s) and are not to be regarded as those of the journal of Research on Engineering Structures and Materials (RESM) organization or related parties. The publishers make no warranty, explicit or implied, or make any representation with respect to the contents of any article will be complete or accurate or up to date. The accuracy of any instructions, equations, or other information should be independently verified. The publisher and related parties shall not be liable for any loss, actions, claims, proceedings, demand or costs or damages whatsoever or howsoever caused arising directly or indirectly in connection with use of the information given in the journal or related means.

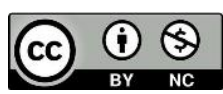

Published articles are freely available to users under the terms of Creative Commons Attribution - NonCommercial 4.0 International Public License, as currently displayed at here (the "CC BY - NC"). 


\title{
Research on Engineering Structures \& Materials
}

journal homepage: http://jresm.org

Research Article

\section{Wind performance for a stadium geometry}

\author{
Elton Hala ${ }^{\mathrm{a}}$
}

Department of Architecture, Polytechnic University of Tirana, Albania

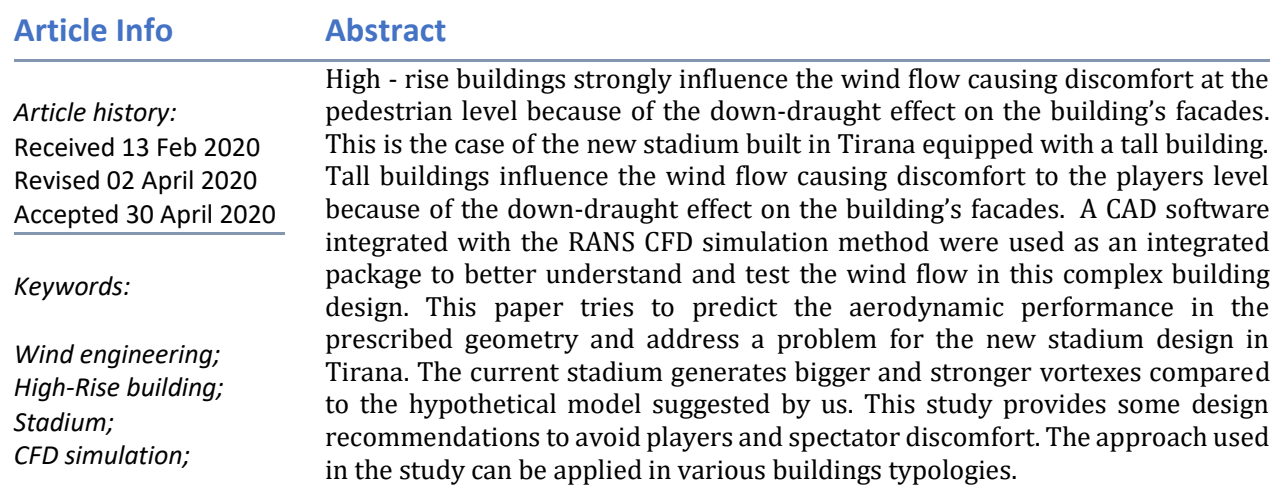

(C) 2020 MIM Research Group. All rights reserved.

\section{Introduction}

Inconsistent winds flow between buildings hence, they are considered fluids that unexpectedly change their directions [1]. The way the air flows across the urban context is a complex fluid flow phenomenon [2]. Winds are three-dimensional and multidirectional with combinations of horizontal and vertical elements even though the vertical component is much smaller in the boundary level and often not considered. The impossibility of visualizing the airflow turns into a complex challenge for engineers testing the environmental performance of their planning choices [3]. Wind speed inside cities is affected mainly by the topography and the urban context [4]. Near the surface, wind parameters can differ from the dominant wind flow by cause of artificial and natural obstacles [5]. Because of friction, wind speed nearly disappears at the bottom of the boundary layer. If wind speed suddenly increases, some variations can become unexpected and to greater amplitude similar to "wind gusts" [6].

The issue is important particularly in playing fields where competitors are influenced by instantaneous wind gusts of high accelerations and unpredictable vortexes. Open - air environments offer fans the exceptional experience of enjoying games while yet experiencing the natural climate. Wind conditions in the playing field have a significant impact on the quality and performance of the game [7]. The open space performance is determined by architectural design in interaction with environmental conditions [7]. The existence of strong winds in running fields appears to be interesting, especially while establishing world records. The advantage of tailwind assistance is known for running sports [8]. Therefore, limitations are established into how much wind can assist outdoor athletes if they set a world record. When establishing a world record, the tailwind limit is set to $2 \mathrm{~m} / \mathrm{s}$. If stronger than that, the record cannot be validated [9]. This practice is not

\footnotetext{
*Corresponding author: tonihala@gmail.com

a orcid.org/0000-0001-8959-624X

DOI: http://dx.doi.org/10.17515/resm2020.181st0213

Res. Eng. Struct. Mat. Vol. 6 Iss. 4 (2020) 411-423
} 
applied in football fields where no running records are registered. Anyway, in most cases, the football players adopt their abilities and skills also to wind speed and its direction. High-velocity wind can cause a change in ball acceleration. Also, unexpected wind gusts may influence the way they direct the ball in the air.

This is the case of the new central stadium built in Tirana. After different attempts to find financial aid, finally, in May 2016 the very last game at the outdated old stadium took place. The construction lasted for two years and in 2019 the newly designed stadium was presented. Inside the new structure, there is no room for a running track giving space to over 22,000 spectators, all covered by cantilever structures. The stadium was built as a public-private partnership agreement with a construction company that also built a multifunctional area. Quite unique was the presentation of a high-rise building included in the stadium perimeter.

Tall buildings often show captivating elegant profiles, but the higher they are, the stronger the wind blows on their top [6]. The air in high altitude moves much faster compared to that on the ground [10]. Many studies emphasize that tall buildings are strongly influencing the wind flow causing discomfort at the pedestrian level because of the downdraught effect on the building's facades [11]. The design team also proposed a tall building of 100 meters, attached to the new stadium, with different functions in particular, hotels, shops, parking spaces, as indicated in (Fig. 1).

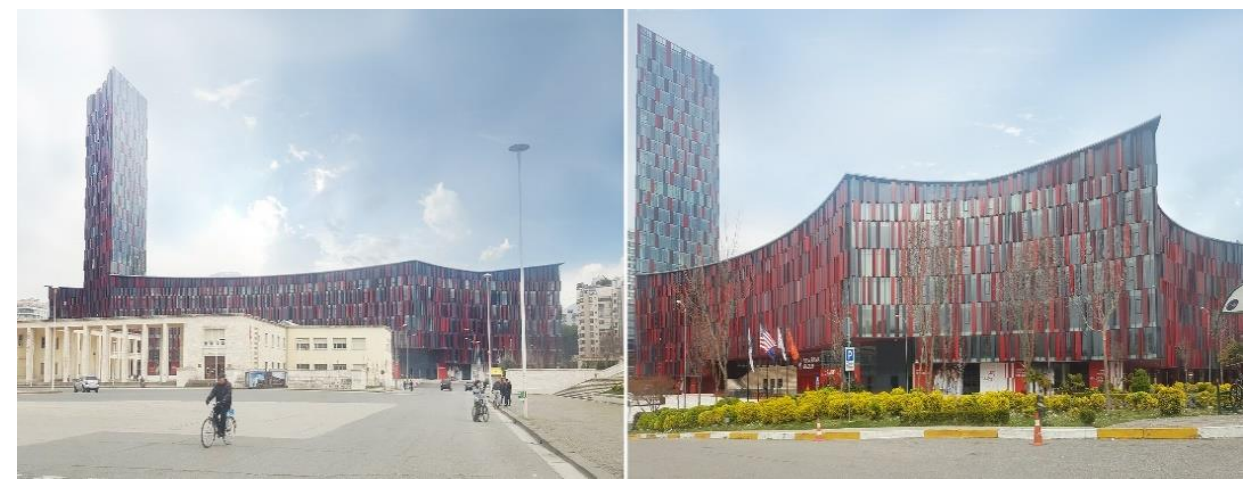

Fig. 1 Views outside the stadium. Photo by Elton Hala

The mass of air down-draught from tall buildings can cause unpleasant effects, most times leading to pedestrians' discomfort and where the wind is at high velocity, it may direct even safety issues. A tall building similar to the one attached in this stadium, can be disadvantageous to football players in the playing field. With the presence of the tall building, the new stadium might have an area in the playing field exposed to high-velocity winds and vortexes.

This paper tries to predict the aerodynamic performance in the inner geometry and discuss a problem related with the stadium design. To direct a possible problem with the stadium design requires considering different elements, in particular external geometry, obstacles, orientation, and so on. The prediction is made using computational techniques, repeatedly been used to assess the wind into the urban environment [12]. Relying solely upon the designer's judgement regarding the wind flow has led often to misinterpretation and confusion of this phenomenon. The urban wind is difficult to be predicted, since every individual city has distinctive layouts therefore, engineers should control in advance the wind effect in their planning choices throughout various methods. Computational fluid dynamics (CFD) mathematical method is frequently applied for wind flow analysis [13]. The CFD simulations help engineers to assess the effects of their planning choices. Much 
research is done to visualize and factor the wind flow, even though it remains a complex fluid flow phenomenon. The CFD simulation presents many advantages toward the in-field measurements or the wind tunnel [14]. The CFD is used for the last 50 years as a tool to study many aspects of the urban environment [12].

The Reynolds-averaged Navier-Stokes (RANS) mathematical model is highlighted by several researchers, as a reasonable accuracy method for many circumstances [15]. A 3D steady RANS CFD simulations in cooperation with local criteria, is used to assess pedestrians' wind comfort around a huge football stadium in Amsterdam. The RANS model was also used to determine the wind flow patterns of a stadium architecture [16]. The steady-state RANS CFD mathematical model can also be used to assess the wind flow nearby and inside a stadium [17].

\section{Method}

It was created a 3D model in real scale maintaining the exact stadium geometry using the CAD software package. In the 3D model, small architectural details were considered incapable to influence the wind flow, therefore, they were not presented in this model. Also, the stadium surroundings were not included in the model since the main purpose of the paper is to investigate what happens inside the playing field and not outside the specified geometry. The CAD model was exported as a stereolithography (STL) file, ready to merge in the CFD package.

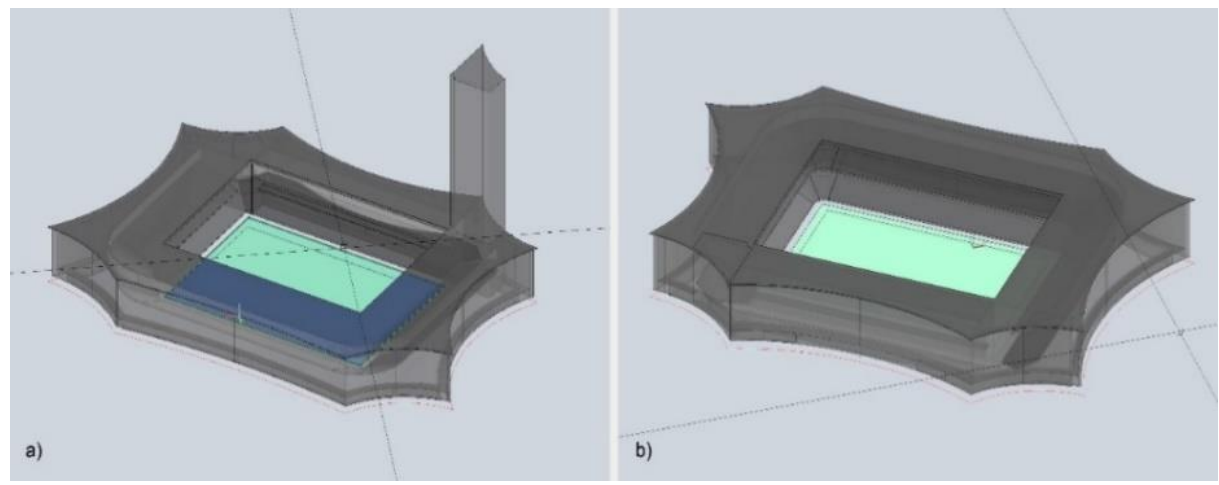

Fig. 2. Three-dimensional models built in CAD; a) model-A with tall building;

b) hypothetical model-B

The import wasn't executed directly from the CAD file since they use meshes made by triangles that repeatedly intersect with triangles of other objects, consequently, they are considered as topologically incorrect. The CFD software adopts a special "shrinkwrapping" mesh topologically correct and can be therefore used as a model boundary for the generation of the Stadium Model. The RANS CFD simulations have always been used for the evaluation of pedestrian wind comfort and safety in urban areas [18]. Hence, it was considered useful also for this evaluation. The 3D model is shown in the (Fig. 2).

\subsection{Wind speed and direction}

The area where the stadium was built, and its microclimate were both essential for design values. The wind climate was provided from the Albanian Geo-Science Institute AGS database and the Weather Spark. They represent average values for a specific period when the wind takes effect. Over the course of the year, the mean wind speed for the stadium area varies from $0 \mathrm{~km} / \mathrm{h}$ to $20 \mathrm{~km} / \mathrm{h}$, while the maximum hardly exceeds $35 \mathrm{~km} / \mathrm{h}(10 \mathrm{~m} / \mathrm{s}$ ) starting from November to February. The wind speed at this level $(10 \mathrm{~m} / \mathrm{s})$ was chosen as 
the worst-case scenario hence, this parameter was applied in the CFD simulation. It was chosen a second scenario with the wind speed at a yearly coincidence of $20 \%$. The wind speed at $4 \mathrm{~m} / \mathrm{s}$ matched our criteria for this simulation. Wind speed lower than $3 \mathrm{~m} / \mathrm{s}$ was considered acceptable and insignificant.

The northwest wind direction was the only one chosen for the simulation since the tall building in the stadium perimeter coincided also with this orientation. According to AGS, the wind is most often from the northwest for 2.8 months, from May 27 to August 22, with a peak percentage of $36 \%$ on June 28 .

\subsection{The criteria}

The criteria to be used for assessment of pedestrian wind conditions have been developed through analysis and experience. Most of these criteria try to set a boundary wind speed over a possibility to occur [19]. The wind speed $4-5 \mathrm{~m} / \mathrm{s}$ for more than $5 \%$ of the time is considered a nuisance for most activities according to many studies, [20], [21], [22], and more recent studies [23], [24], [25], and wind mitigation strategies are typically recommended for these open areas. Thus, the wind speed at $4-5 \mathrm{~m} / \mathrm{s}$ seems to be the comfort limit also for individuals engaged in sports activities in particular soccer games.

\subsection{Simulation}

The first simulation tests the exact stadium geometry two wind speed $(10 \mathrm{~m} / \mathrm{s}$ as the worstcase scenario and $4 \mathrm{~m} / \mathrm{s}$ typically windy day). This model was labeled "Model-A" and the simulations was named $\mathrm{A} 10$ and $\mathrm{A} 04$. The second simulation addresses a possible problem with the stadium design. This model was also evaluated in two wind speeds $(10 \mathrm{~m} / \mathrm{s}$ and $4 \mathrm{~m} / \mathrm{s}$ ). This hypothetical model was labeled "Model-B". The analysis was taken in three horizontal plans 5-10-20m, altogether covering the effective playing field area. Hence, it was observed the wind performance in vertical plans only for Model-A.

\subsection{Flow parameters}

The result of the calculation is a three-dimensional field of velocity and pressure covering the entire computational domain. The simulation domain dimensions are automatically set to fit the model size but can be modified if needed. The simulation parameters were as follows:

Parameters for Model-A and Model-B running at $10 \mathrm{~m} / \mathrm{s}$ :

- CFD Domain dimension: $\mathrm{X}=1,700 \mathrm{~m} ; \mathrm{Y}=1,000 \mathrm{~m} ; \mathrm{Z}=450 \mathrm{~m}$;

- Detailed mesh information: 773,597 cells;

- Used nodes: 874,985;

- Original model drag force sum: $F x=595.087 \mathrm{kN}, F y=46.668 \mathrm{kN}, \mathrm{Fz}=593.101 \mathrm{kN}$;

- Simplified model drag force sum: $F x=584.305 \mathrm{kN}, \mathrm{Fy}=54.106 \mathrm{kN}, \mathrm{Fz}=631.64 \mathrm{kN}$;

- Wind boundary profile : $150 \mathrm{~m}$;

- Wind tested: $10 \mathrm{~m} / \mathrm{s}$.

Parameters for Model-A and Model-B running at 4m/s:

- CFD Domain dimension: $\mathrm{X}=1700 \mathrm{~m} ; \mathrm{Y}=1000 \mathrm{~m} ; \mathrm{Z}=150 \mathrm{~m}$;

- $\quad$ Detailed mesh information: 782,385 cells;

- Used nodes: 886,952;

- Original model drag force sum: $F x=60.533 k N, F y=14.925 k N, F z=93.097 k N$;

- Simplified model drag force sum: $F x=59.125 \mathrm{kN}, \mathrm{Fy}=54.066 \mathrm{kN}, \mathrm{Fz}=96.25 \mathrm{kN}$;

- Wind boundary profile: $150 \mathrm{~m}$; 
- Wind tested: $4 \mathrm{~m} / \mathrm{s}$.

Wind parameters ware as follows:

- Viscosity: $0.000015 \mathrm{~m}^{2} / \mathrm{s}$; This is considered the typical wind viscosity in open domains. The viscosity however depends on

- Air density: $1.250 \mathrm{~kg} / \mathrm{m}^{3}$; The density in general is directly related to many factors such as: air temperatures, atmospheric pressure, and humidity. This value explains the resistance of the air against the deformation. This density value is equal to the air at around $15^{\circ} \mathrm{C}$.

- Convergence Criterion: (P-Residual) $=0.001$ This parameter indicates the accuracy of the model from the idealized model in percentage.

Turbulence Model Properties: To predict the turbulence flow so called (DNS) Direct Numerical Simulation need to have powerful computational availability. The CFD sofware used for these simulations uses a diverse method where wind parameters are averaged in mean and fluctuating components. It uses a modified set of air flow equations referred as RANS equations, mentioned also above.

- Flow model: The turbulence properties are included as required. The k- $\varepsilon$ turbulence model present two equations in RANS for turbulent flow conditions: the first one represents the transport equation of the turbulence kinetic energy $\mathrm{k}$, and the second equation manage the transport of the dissipation rate $\varepsilon$ of $\mathrm{k}$. In these simulations no analytic calculation was provided. This model is popular among users since it engages less computational amounts to solve the equations. In our CFD software the equations values are automatically set based in the initial and the boundary conditions and this is considered to be the simplest turbulence model. The k- $\omega$ model probably would have given different outcome around the edges, but the used k- $\varepsilon$ model has also a credible result for a wide range of turbulence flows.

The sofware defines automatically the turbulent kinetic energy $k$ and turbulent dissipation rate $\varepsilon$. The users sets the intensity of the turbulent flow.

- Turbulence kinetic energy $k: 0.015 \mathrm{~J} / \mathrm{kg}$

- Dissipation rate: $\varepsilon: 4.6842 \mathrm{E}-06$

- Turbulence intensity i: $10 \%$ The typical turbulence air motion ranges between $5 \%$ to $20 \%$. This value was set in between these values.

\section{Results}

\subsection{Simulation domain parameters}

The first simulation was considered the worst-case scenario running a wind velocity of $10 \mathrm{~m} / \mathrm{s}$. The wind evaluation in different highs is presented in the (Fig. $3 \mathrm{a}, \mathrm{b}, \mathrm{c}$, the current stadium "Model-A" with the presence of the tall building and $\mathrm{d}, \mathrm{e}, \mathrm{f}$, the stadium without the tall building presence, "Model-B").

Model-A simulation domain parameters: Dimensions: $X=1700 \mathrm{~m} ; \mathrm{Y}=1000 \mathrm{~m} ; \mathrm{Z}=450 \mathrm{~m}$. Detailed mesh information for this model: 773,597 cells, 874,985 nodes. Original model drag force sum: $F x=595.087 \mathrm{kN}, \mathrm{Fy}=46.668 \mathrm{kN}, \mathrm{Fz}=593.101 \mathrm{kN}$. 

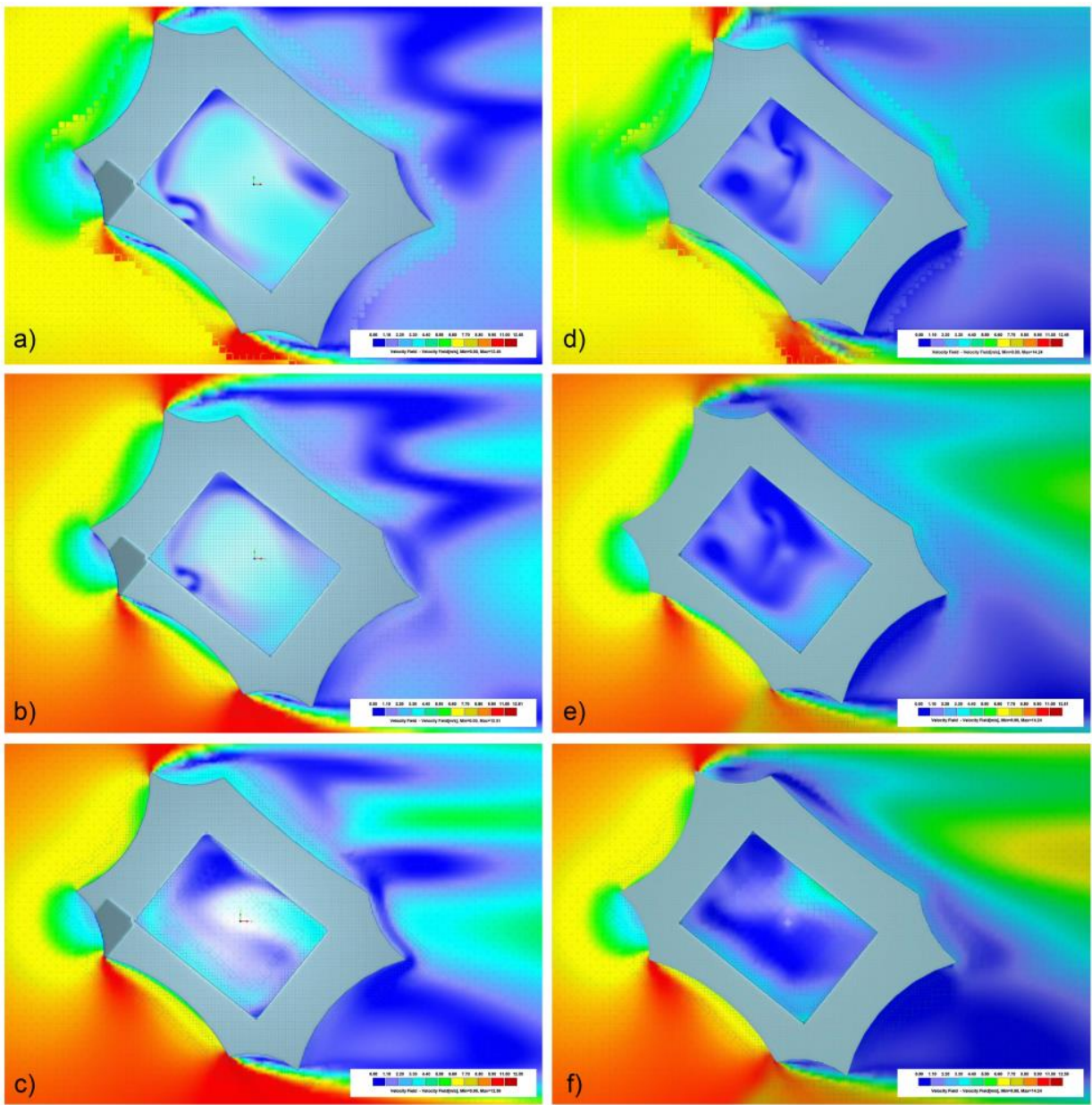

Fig. 3. Velocity field - simulation $10 \mathrm{~m} / \mathrm{s}$; a), b), c) current stadium model; d), e), f) hypothetical model - no tall building presence

The second simulation tests a lower wind speed of $4 \mathrm{~m} / \mathrm{s}$ and it corresponds to a typical windy day. Model-B simulation domain parameters: Dimensions: $X=1700 \mathrm{~m} ; \mathrm{Y}=1000 \mathrm{~m}$; $\mathrm{Z}=150 \mathrm{~m}$. Detailed mesh information for this model: 782,385 cells, 886,952 nodes. Original model drag force sum: $\mathrm{Fx}=60.533 \mathrm{kN}, \mathrm{Fy}=14.925 \mathrm{kN}, \mathrm{Fz}=93.097 \mathrm{kN}$.

\subsection{Velocity field plans}

Results obtained in 5, 10, 20 meters high show the maximum wind velocity of $4.23 \mathrm{~m} / \mathrm{s}$ in the model-A and $73 \%$ of the playing area is affected by wind speed at $3-4 \mathrm{~m} / \mathrm{s}$. Although Model-B generates a maximum registered velocity of $3.52 \mathrm{~m} / \mathrm{s}$ and $24 \%$ of the playing area is prevailed by wind speed over $3 \mathrm{~m} / \mathrm{s}$. 

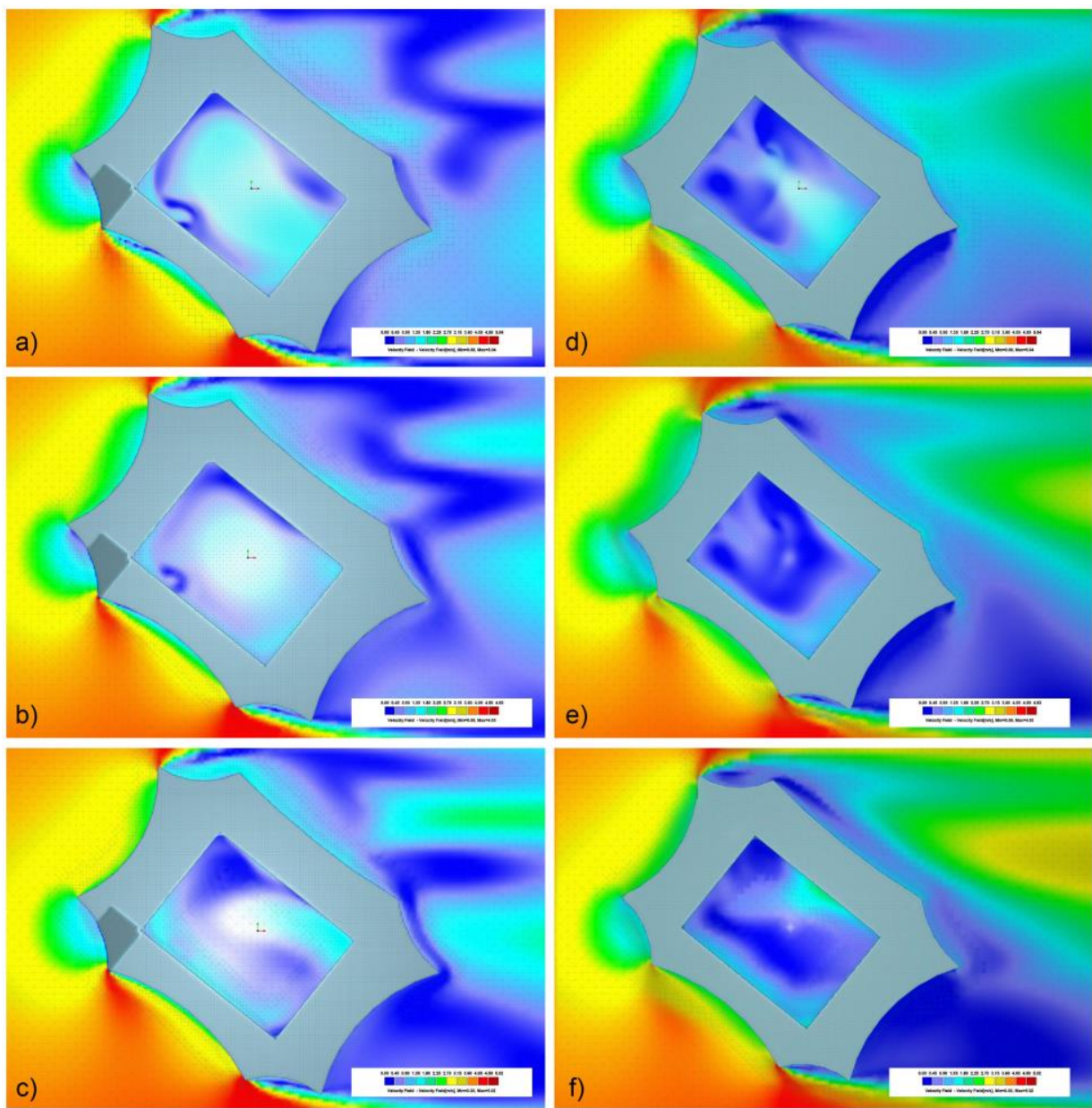

Fig. 4. Velocity field - simulation $4 \mathrm{~m} / \mathrm{s}$; a), b), c) current stadium model; d), e), f) hypothetical model - no tall building presence

Results obtained in the second simulation in 5, 10, 20 meters high show the maximum registered velocity of $1.67 \mathrm{~m} / \mathrm{s}$ in the model-A and $72 \%$ of the playing area is affected by wind speed at $1-2 \mathrm{~m} / \mathrm{s}$. Model-B generates a maximum wind velocity of $1.35 \mathrm{~m} / \mathrm{s}$ and $25 \%$ of the playing area is prevailed by wind speed over $1.5 \mathrm{~m} / \mathrm{s}$. These results were also confirmed from the streamlines graphs both in plan views and sections (Fig. 4).

There were changes in the wind speed at different altitudes. The area affected mostly from high-velocity wind was discovered at a high 0-5 meters referring to the playing ground. This area is loaded on high velocities winds, vortexes, and turbulence air. The higher the altitude inside the stadium, the more likely the wind reduce its speed.

\subsection{Vertical Section}

The vertical plans were set to observe particularly the worst-case scenario, primarily across the tall building. Vertical planes were not set in the second testing speed, since these results can be used to assert the results discovered in horizontal plans. The results in (Fig. 5) approve that the current stadium can create more vortices to greater wind speed, 
especially in the playing ground. Winds affected an extensive area, over $80 \%$ at $0-5 \mathrm{~m}$ above the playing ground at $3-4 \mathrm{~m} / \mathrm{s}$ for the test running at $10 \mathrm{~m} / \mathrm{s}$.
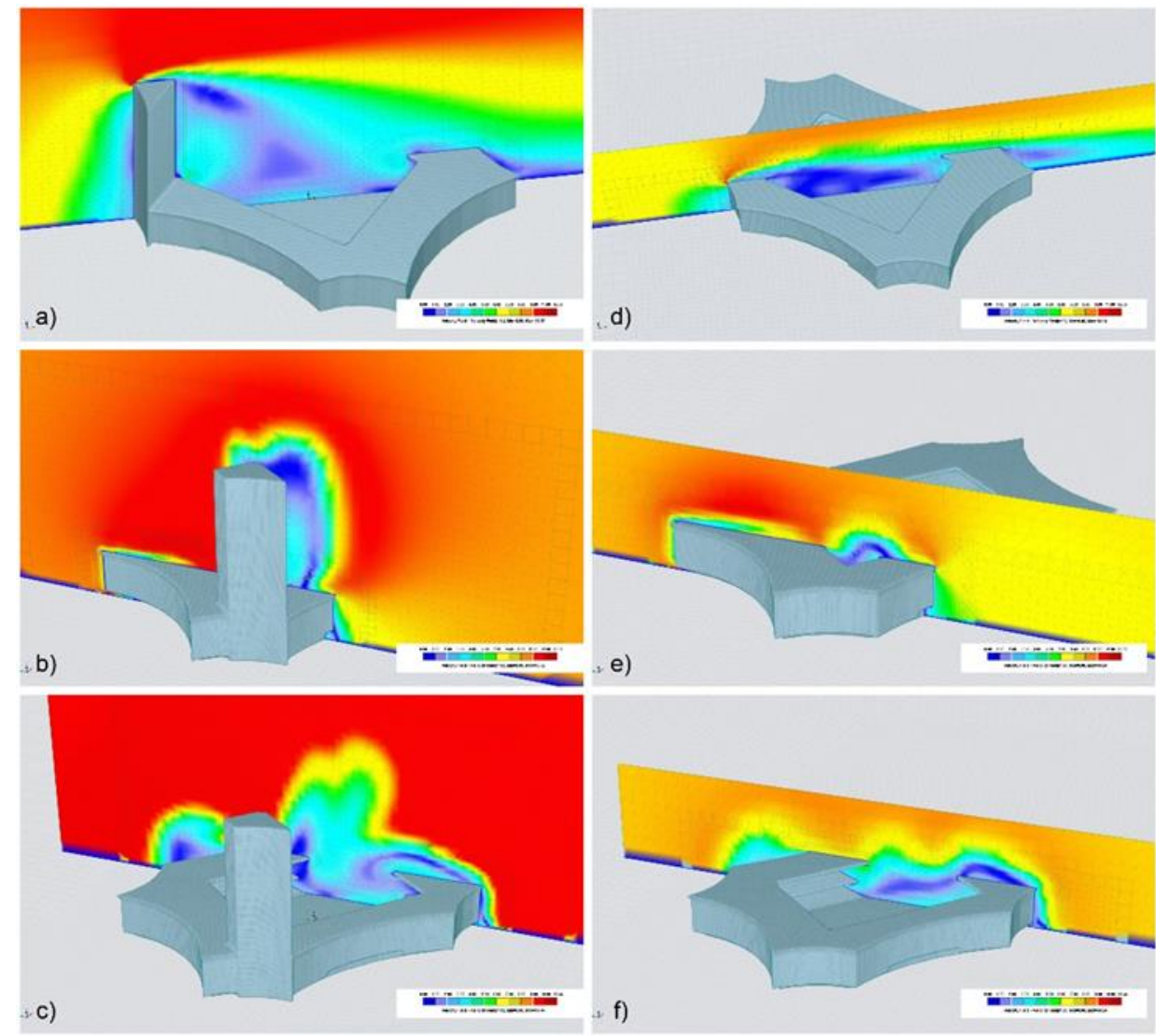

Fig. 5. Velocity field, axonometric views - first simulation $10 \mathrm{~m} / \mathrm{s}$; a), b), c) current stadium model; d), e), f) hypothetical model - no tall building presence

\subsection{Tall building}

The tall building connected with the stadium in the Model-A is capable of creating vortices more than 100 meters high. By observing the streamlines, (Fig. 6a), the tall building can generate turbulence for a wide area of more than $400 \times 100 \times 40 m$. Several vortexes are generated especially below the tall building in the north-eastern direction at a speed of $1.0 \mathrm{~m} / \mathrm{s}-1.4 \mathrm{~m} / \mathrm{s}$ especially in a worst-case scenario Model-B (Fig. 6b). The vortexes are also present in the Model-B even though at a lower speed. These vortexes are not generated in a typically windy day scenario (Fig. 6b).

\subsection{Pressure field}

In the pressure field graphs, the playing area is substantially less charged at Model-B. For tests running at $10 \mathrm{~m} / \mathrm{s}$, results show the maximum dynamic pressure of $63.0 \mathrm{~Pa}$ to $32.8 \mathrm{~Pa}$ between our models. Hence, the Model-B is emerging in the system a lower number of 
interacting particles, thus a dropped pressure is registered in the graphs (Fig. 7). The surface pressure in the building facades does not reveal any useful information to be used for assessing the wind flow inside the stadium.

Model-A is capable of producing more vortices in the playing field to greater wind speed in both scenarios.
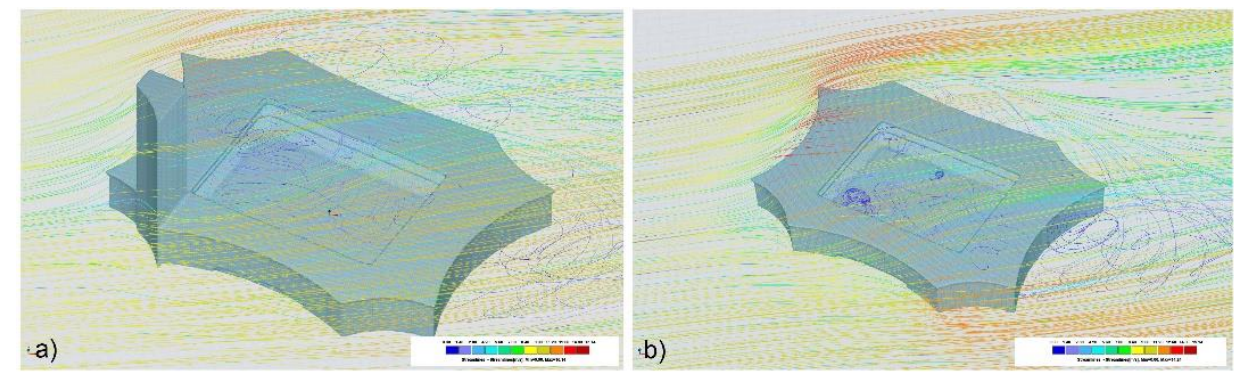

Fig. 6. Streamlines in the first simulation $10 \mathrm{~m} / \mathrm{s}$; a) current stadium;

b) hypothetical model

\section{Discussions}

By comparing these two geometrical models in various wind conditions, important findings were discovered. Referring to wind engineering, our hypothetical model (unequipped with a tall building in the stadium proximity) was able to get better results by offering more comfort in the playing field in contrast with the current stadium geometry.

Compared to the current stadium design, the hypothetical Model-B, have smaller areas exposed to high-velocity air. This result was detected in every testing wind speed. For us, this was a perception of a problem with the current stadium design.

In a windy day blowing from the northeast, not unusual for the area, the current stadium will generate bigger and stronger vortexes comparing to the hypothetical model offered from us. Particularly these effects happen 0-5 meters above the playing ground, which is considered an intense playing area. It was also detected an area in which the vortexes are generated easily. This area was detected near the tall building base.

Model-B was also responsible for creating a lighter vortices, particularly around the playing ground. Vortexes were displayed also in the hypothetical model. These effects probably are found in all open fields which are surrounded by high barriers in particular stadium stairs. Our hypothetical model has offered tolerated wind speeds also in the stairs and the surrounding area outside the stadium. The wind circulation in both scenarios was to a lower speed comparing to the current stadium design.

Based on a general understanding of aerodynamics, the following explanation were found for the model's contrasts. The present stadium is equipped with a 100 meters tall building with a direct connection with the playing field (Fig. 8). The presence of the tall building in the stadium perimeter was unusual among stadium designs. The tall building can serve also as a wind catcher hence, it directs more wind at high velocities mostly as a result of 
the down-draught effect [11]. The wind gains a lot of speed because of tall buildings and opened corridors it passes through [27].

The first simulation tested a scenario running at a velocity of $10 \mathrm{~m} / \mathrm{s}$ and the high-rise building represented in the Model-A was able to increase the wind speed in the playing field to a maximum of at $4.23 \mathrm{~m} / \mathrm{s}$. The wind speed $4-5 \mathrm{~m} / \mathrm{s}$ is considered a nuisance for most activities, including outdoor sports, according to many studies, [20], [21], [22], and recent studies like [23], [24], [25]. Thus, the wind speed at $4-5 \mathrm{~m} / \mathrm{s}$ seems to be the limit also for people involved in sports activities in this stadium. Hence, if the wind coincides with the tower direction at $10 \mathrm{~m} / \mathrm{s}$ unpleasant effects can be seen with the players and the soccer ball trajectories. The phenomena mainly emphasize the wind gusts, which is defined as a short-duration or a maximum of the predominant wind speed [28].
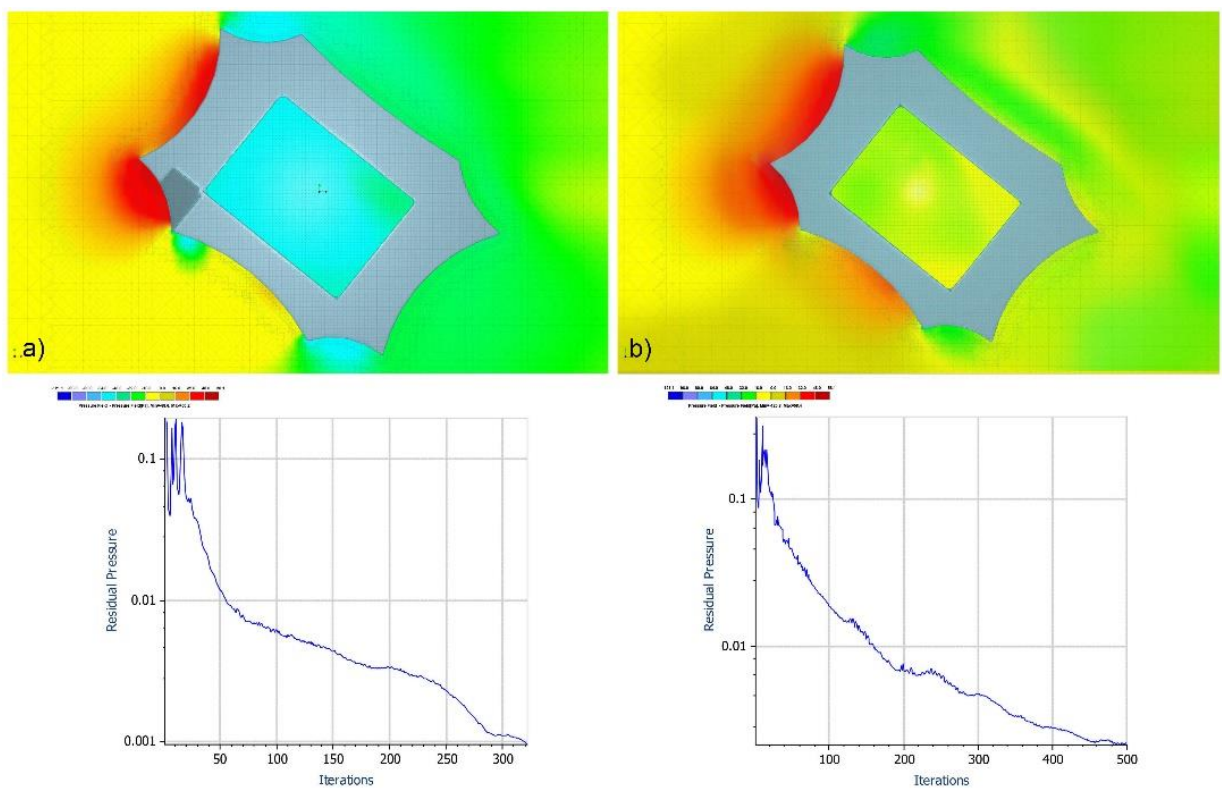

Fig. 7. Pressure field and residual pressure in the first simulation $10 \mathrm{~m} / \mathrm{s}$; a) current stadium; b) hypothetical model

The stairs geometry can also contribute to intensifying the circular air motion. A uniform flow around a circular shape creates a nonlinear system used to generate vortexes [29]. Particularly this effect is amplified from the gigantic cantilever canopies provided in the stadium to serve as rain shelters for spectators enjoying outdoor sports activities. Van [16], pointed out that architects often design stadium shelters with only vertical rainfall in mind, neglecting the wind effect that can also sweep the rain onto the seats.

\section{Conclusions}

- $\quad$ Computer-Aided Design is yet a valuable approach to design the building shape and the wind-flow patterns can be determined efficiently by Reynolds-averaged NavierStokes, Computational Fluid Dynamics (CFD) simulation. CAD software integrated with the RANS CFD simulation method can be used as an integrated package to better understand and evaluate the wind flow in this complex building design. Since the air 
molecules are invisible, the CFD is yet a valuable tool to visualize the wind flow in every environmental domain.

- The major concern of the present stadium design was related to the tall building attached to the stadium geometry. Most of the unpleasant effects on the playing field are addressed to the presence of the tall building and its close distance with the playing field. This result was shown by simply proposing the same model geometry unequipped with this 100-meter-tall building. The situation changed efficaciously by reducing the wind speed up to $2.9 \mathrm{~m} / \mathrm{s}$ in the playing field.

- Vortexes were present in both models due to the closed shaped stadium. The air is obstructed and moves in a circular motion around the stairs and with nowhere to go, it injects in the playing field. Simulation results suggest that there will be a bigger area of high velocity turbulence. In a strong windy day, the wind speed $(4.23 \mathrm{~m} / \mathrm{s})$ generated in the playing field will not be acceptable. The close shapes stadium probably needs mitigation strategies, for instance openings.

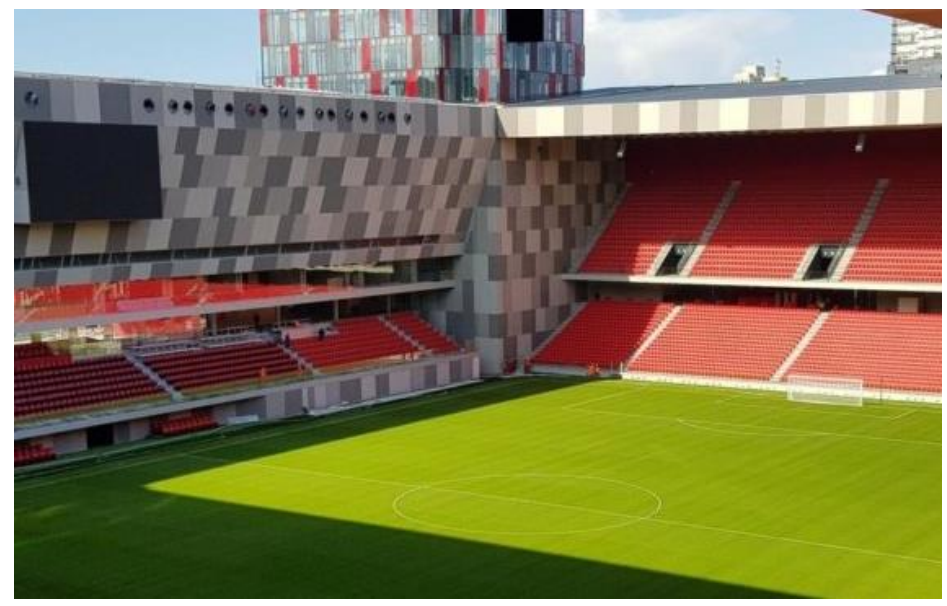

Fig. 8. Stadium Interior. Photo by Elton Hala

\section{Further studies}

Tall buildings often present fascinating elegant silhouettes, but the higher they are, the stronger the wind is conveyed in their base. Hence, their effect on the playing ground might be bigger. The authorities should pay attention to tall buildings co-existence close to the playing fields. Further studies also can be done to better understand how the vortexes are generated and how the surroundings can generate or prevent their creations. Future research might focus on understanding the way the ball bypasses the player's expected trajectory on a windy day and how it affects their reactions.

\section{References}

[1] Wohland J., Wohland J., Omrani NE., Witthaut D., Witthaut D., Keenlyside N. Inconsistent Wind Speed Trends in Current Twentieth Century Reanalyses. Journal of Geophysical Research, 2019;124(4):1931-1940. https://doi.org/10.1029/2018JD030083

[2] Orlandi P. Fluid flow Phenomena: A Numerical Toolkit, Dordrecht, Kluwer. 2000. https://doi.org/10.1007/978-94-011-4281-6 
[3] Max N., Crawfis R., Williams DN. Visualizing wind velocities by advecting cloud textures. 1992.

[4] Hitchcock PA., Kwok KC., Wong K., Shum KM. The effects of topography on local windinduced pressures of a medium-rise building. Wind and Structures, 2010;13(5): 433449. https://doi.org/10.12989/was.2010.13.5.433

[5] Zhang H., Pu Z., Zhang X. Examination of Errors in Near-Surface Temperature and Wind from WRF Numerical Simulations in Regions of Complex Terrain. Weather and Forecasting, 2013;28(3):893-914. https://doi.org/10.1175/WAF-D-12-00109.1

[6] Crosbie J, Perry D, Smith Th. Buildings at risk: Wind design basics for practicing architects. Manual prepared by the American Institute of Architects (AIA) 2008.

[7] Goliger AM. Wind-tunnel testing of sports stadia to optimize their use and safety. J. S. Afr. Inst. Civ. Eng., Midrand , Apr. 2010; 52, (1).

[8] Dapena J., Feltner ME. Effects of Wind and Altitude on the Times of 100-Meter Sprint Races. International journal of sport biomechanics, 1987;3(1):6-39. Retrieved 42 , 2020. https://doi.org/10.1123/ijsb.3.1.6

[9] IAAf - International Association of Athletics Federations. Competition Rules. 2017; 269281.

[10] Simiu E, Scanlan SH. Wind Effects on Structures. John Wiley and Sons, Canada. 1996.

[11] Hala E, Nepravishta F, Panariti A. The wind flow effects and high-rise buildings in urban spatial morphology. Cities in Transitions, Proceedings of the 1st International Forum on Architecture and Urbanism, 14-16 December 2017 Tirana Albania. Publisher: La scuola di Pitagora Editrice. 2019. pp 52-56, ISBN 978-88-6542-679-1, ISBN 978-88-6542-695-1.

[12] Qingyan Y. Chen. Using computational tools to factor wind into architectural environment design. Energy and Buildings, 2004; 36: 1197-1209. https://doi.org/10.1016/i.enbuild.2003.10.013

[13] Reiter S. Assessing wind comfort in urban planning. Environment and Planning B: Planning and Design, 2010;37(5): 857-873. https://doi.org/10.1068/b35154

[14] Blocken B, Janssen WD, Van Hooff J. CFD simulation for pedestrian wind comfort and wind safety in urban areas: General decision framework and case study for the Eindhoven University campus. Environmental Modelling \& Software, 2012;30: 15-34. https://doi.org/10.1016/i.envsoft.2011.11.009

[15] Blocken B, Persoon J. Pedestrian wind comfort around a large football stadium in an urban environment: CFD simulation, validation and application of the new Dutch wind nuisance standard. Journal of Wind Engineering and Industrial Aerodynamics 2009;97(5-6), 255-270. https://doi.org/10.1016/j.jweia.2009.06.007

[16] Van Hooff T, Blocken B, Van Harten M. 3D CFD simulations of wind flow and winddriven rain shelter in sports stadia: Influence of stadium geometry. Building and Environment, 2011;46(1): 22-37. https://doi.org/10.1016/i.buildenv.2010.06.013

[17] Mei W, Qu M. Evaluation and Analysis of wind flow for a football stadium. Science Direct. 2016;145: 774-781. https://doi.org/10.1016/j.proeng.2016.04.101

[18] Wu H, Kriksic F. Designing for pedestrian comfort in response to local climate. Journal of Wind Engineering and Industrial Aerodynamics, 2012;104-106: 397-407. https://doi.org/10.1016/j.jweia.2012.02.027

[19] Janssen WD, Blocken B, Van Hooff T. Pedestrian wind comfort around buildings: comparison of wind comfort criteria based on whole-flow field data for a complex case $\begin{array}{llll}\text { study. Building } & \text { and }\end{array}$ https://doi.org/10.1016/i.buildenv.2012.10.012

[20] American Society of Civil Engineering - ASCE. Task Committee on Outdoor Human Comfort of the Aerodynamics Committee of ASCE, Outdoor Human Comfort and its Assessment, American Society of Civil Engineers, Reston, VA. 1979. 978-0-7844-06847 (ISBN-13) | 0-7844-0684-7 (ISBN-10). 
[21] Melbourne WH. Criteria for environmental wind condition. Journal of Wind engineering \& Industrial Aerodynamics 1978; $3:$ 241-24. https://doi.org/10.1016/0167-6105(78)90013-2

[22] Murakami S, Iwasa, Morikawa Y. Study on acceptable criteria for assessing wind environment on ground level based on residents' diaries. Journal of Wind Engineering and Industrial Aerodynamics. 1986;24: 1-18. https://doi.org/10.1016/01676105(86)90069-3

[23] Bottema M. A method for optimization of wind discomfort criteria. Build Environmental 2000;35(1): 1-18. https://doi.org/10.1016/S0360-1323(98)00065-1

[24] NEN 8100. Wind comfort and wind danger in the built environment. NEN 8100 Nederlands Normalisatie Instituut Publications. 2006.

[25] Koss HH. On differences and similarities of applied wind comfort criteria. Journal of Wind Engneering and Industrial Aerodynamics 2006; 94: 781-797. https://doi.org/10.1016/j.jweia.2006.06.005

[26] Blocken B. 50 years of computational wind engineering: past, present and future. Journal of wind engineering and industrial 2014; 129: 69-102. https://doi.org/10.1016/j.jweia.2014.03.008

[27] Hala E. Turning the effect of urban wind into an asset: its impact in climate-sensitive urban design. Proceedings of the International Conference for Civil Engineering, In English, ICCE2017, 12-14 October 2017 Tirana Albania, 2017;2:196. ISBN 978-99284429-2-5.

[28] Suomi I, Vihma T. Wind Gust Measurement Techniques-From Traditional Anemometry to New Possibilities. Sensors. 2018; 18(4): 1300 https://doi.org/10.3390/s18041300

[29] Vasconcelos GL, Moura MN, Schakel AMJ. Vortex motion around a circular cylinder. Physics of Fluids. 2012; 23(12). https://doi.org/10.1063/1.3667269 